\title{
NEAR-REAL TIME HAZARD MONITORING AND INFORMATION DISSEMINATION THROUGH INTEGRATION OF REMOTE SENSING, GIS, NUMERICAL MODELLING, WEB APPLICATIONS AND SOCIAL MEDIA
}

\author{
M. Makinano- Santillan ${ }^{1,2, *}$, J. Serviano ${ }^{1}$, C.K. Rubillos $^{1}$, A. Amora ${ }^{1}$, J.R. Santillan ${ }^{1,2}$, E.M. Morales ${ }^{1}$, J.T. Marqueso ${ }^{1}$, A.L. Gingo ${ }^{1}$ \\ ${ }^{1}$ Caraga Center for Geo-Informatics, Caraga State University, Ampayon, Butuan City, 8600, Philippines \\ ${ }^{2}$ Department of Geodetic Engineering, College of Engineering and Geo-Sciences, Caraga State University, \\ Ampayon, Butuan City, 8600, Philippines - (jrsantillan, mmsantillan) @ carsu.edu.ph
}

Commission III, WG III/10

KEY WORDS: Remote Sensing, GIS, Numerical Modelling, Flood, Hazard Information Dissemination, Web-based platforms, Social Media

\begin{abstract}
:
In mitigating and helping lessen the possible effects and damages of disaster to the communities, the transmission of information or end products derived from remote sensing and other multidisciplinary technologies into the community should be immediate, accessible and comprehensive to aid in better planning and decision-making procedures. In this paper, we share a hazard information dissemination procedure which integrates the use of outputs derived from numerical models, web applications and systems as well as the use of social media and telecommunications to promote the utilization of advanced science and technology outputs that could represent and visualize various flooding scenarios through social media and dynamic communication between stakeholders.
\end{abstract}

\section{INTRODUCTION}

The threats and levels of destruction imposed by catastrophes and disasters can devastate communities or immobilize their life chances (Hewitt, 1997). In the Philippines, weather and geophysical-related disasters is a recurring adversity (Lagmay, et al., 2017). Flooding, in particular, is considered to be one of the most destructive among many natural disasters (Santillan, et al., 2016), and Philippines, being referred to as a 'hotbed' of disasters, has been suffering from its damages (Lagmay, et al., 2017). Hence, the continuous need to prepare for forthcoming flood events is deemed to be crucial and important for disaster risk reduction and management.

Given the effects it may bring to the welfare of individuals, families and communities, calamities have sparked and stimulated the systematic utilization of information and communication technology (ICT) methods (Shklovski, et al., 2008). In principle, ensuring that the disaster management and response procedures are effective calls for instantaneous utilization of available information and data (Laituri and Kodrich, 2008). The public and the affected individuals have often encountered cases of not being able to acquire or access timely information necessary to aid then in times of decisionmaking and establishing calmness in times of disasters (Shklovski, et al., 2008).

In light of these, the Philippine government has supported the use of remote sensing and multidisciplinary technologies to initiate community preparedness as there is already a pressing need for accessible and immediate action to mitigate impacts of disasters
(Lagmay, et al., 2017). One of such efforts is the GeoInformatics for the Systematic Assessment of Flood Effects and Risks in the Agusan River Basin (Geo-SAFER Agusan) project.

The Geo-SAFER Agusan Project is one of the component projects of the Geo-informatics for the Systematic Assessment of Flood Effects and Risks towards a Resilient Mindanao (GeoSAFER Mindanao) Program and is being funded by the Philippine Council for Industry, Energy and Emerging Technology Research and Development (PCIEERD) of the Department of Science and Technology (DOST). The project is being implemented by Caraga State University in Ampayon, Butuan City, Philippines through the Caraga Center for Geoinformatics of the College of Engineering and Information Technology. The program is basically an extension to the PhilLiDAR 1. Hazard Mapping of the Philippines using LiDAR program, aimed to produce up-to-date, detailed, and highresolution flood hazard maps for the country's critical major river basins (UP DREAM, 2016; ), that can be used to determine at the household level the houses and structures that are at risk of an impending flood disaster (Santillan, et al., 2016). The project processes and analyses 1-m spatial resolution LiDAR-derived datasets and Interferometric Synthetic Aperture Radar (InSAR) Digital Terrain and Surface Models (DTMs and DSMs), and information extracted from optical and Synthetic Aperture Radar (SAR) remote sensing images, and then utilize these as inputs to numerical simulation models for hydrologic and hydraulic characterization of the basin, and to produce detailed flood hazard maps for different flood scenarios.

\footnotetext{
* Corresponding author
} 


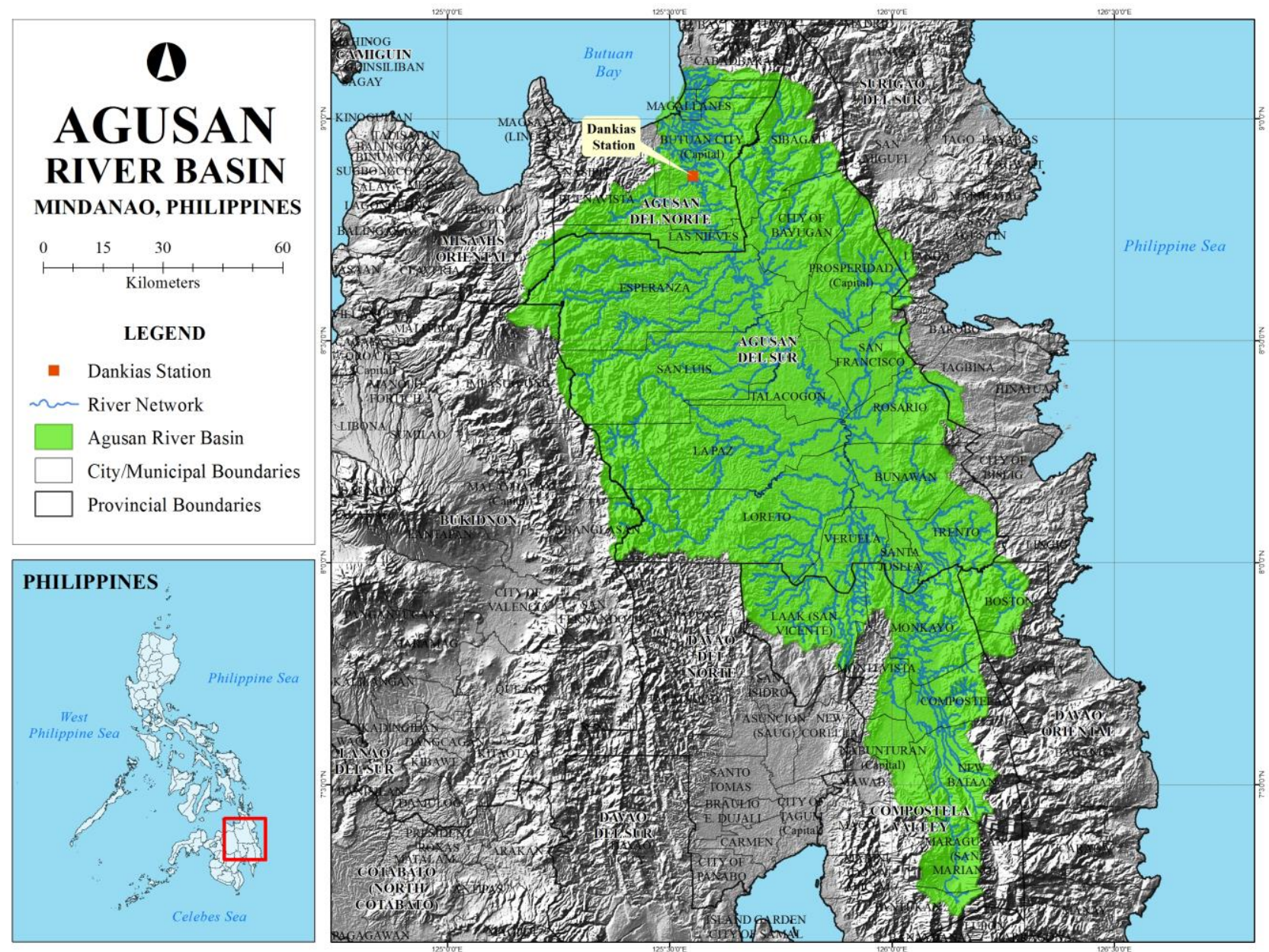

Figure 1. The Agusan River Basin, the project area of the Geo-SAFER Agusan Project.

Alongside its geo-informatics-based activities, the project also conducts near-real time and forecasted simulation of flood models, monitoring on water levels and rainfall status on different river basins on the Provinces of Agusan del Norte and Agusan del Sur and the transmission of the data generated from such activities to the Local Government Units (LGUs) and the general public as part of its hazard information dissemination procedures.

The project covers 14 sub-basins/watersheds in the Agusan River Basin (ARB; Figure 1), the Philippines' third largest river basin (Asian Development Bank, 2004), and a regular subject of flooding every year, particularly during extreme rainfall events. Its activities and end-products are expected to benefit at least 15 cities/municipalities in the Provinces of Agusan del Norte and Agusan del Sur, in which these sub-basins/watersheds are mainly situated.

Despite the government's efforts to implement flood disaster risk reduction and management programs, the need to improvise and provide a more effective method of preparing and capacitating the people remains as a necessity. Hence, the Geo-SAFER Agusan Project continued to search for methods for an effective information dissemination system and increase the project's influence to the LGUs.

This paper expounds on how the hazard information dissemination procedures of the Geo-SAFER Agusan project is being used as a tool in the integration of numerical model outputs, development of web applications and the use of social media in undertaking Disaster Risk Reduction and Managementrelated activities with hopes of empowering and establishing flood resilience in the communities.

\section{METHODOLOGY}

\subsection{Overview}

The hazard information generation and dissemination workflow is presented in Figure 2. In disseminating information related to hazards, the team first identified the necessary data that should be derived and utilized by the project in producing outputs necessary to be disseminated. Identified numerical models and data gathered by the project from the Department of Science and Technology (DOST) were first utilized in developing models and generating flood hazard maps on its covered areas. These outputs were then embedded and integrated into the project's webpage and online applications in order to be utilized for the team's monitoring activities during weather disturbances and tropical cyclones. Prior to the implementation of the project, this process was already introduced to the Disaster Risk Reduction and Management Officers (DRRMOs) and other concerned members of the project's partner LGUs during its courtesy visits and project presentations. All the project's covered areas were also provided with temporary flood hazard maps as bases during the team's monitoring activities while the project is still on-going. 


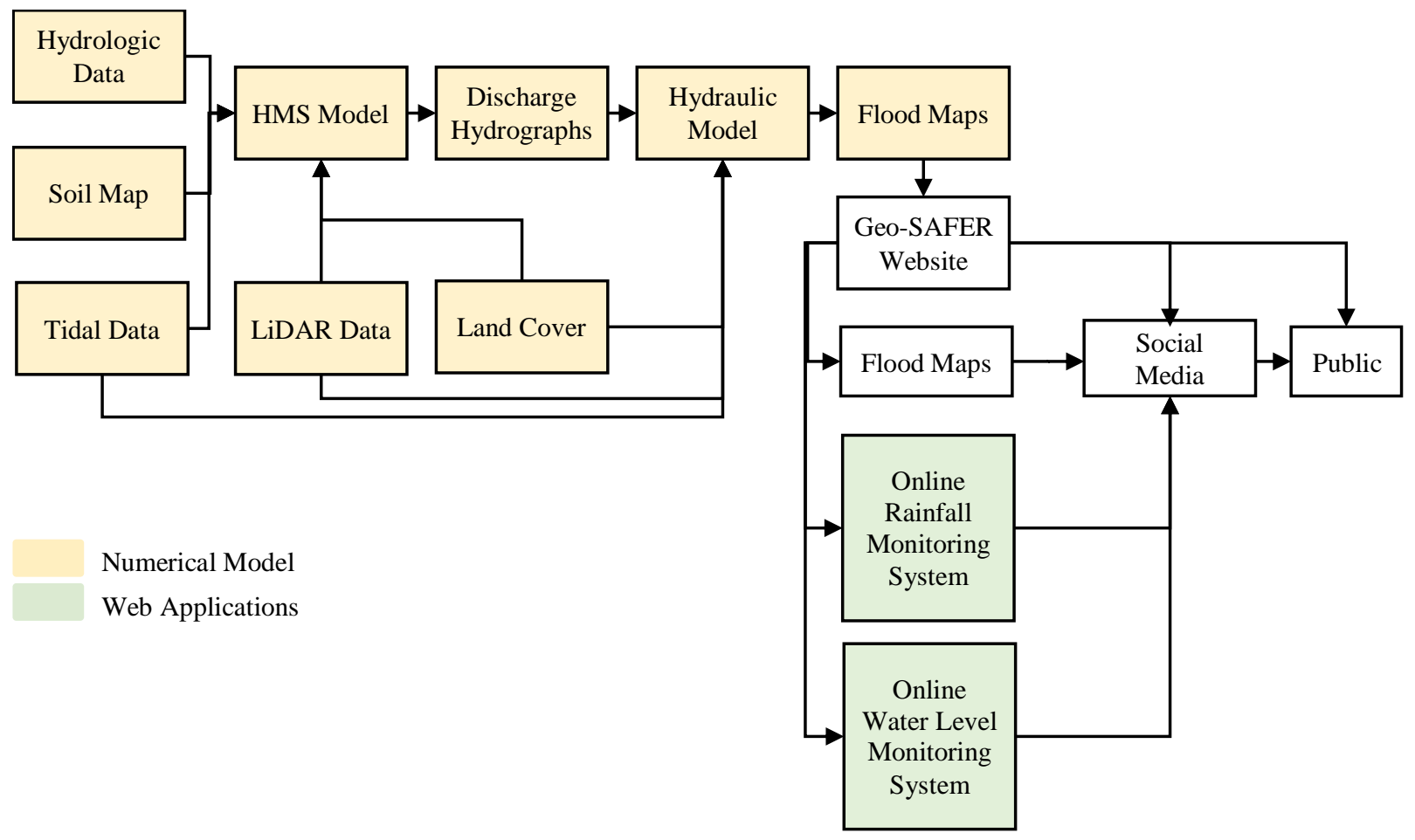

Figure 2. The hazard information generation and dissemination workflow.

\subsection{Development of Numerical Models}

2.2.1 HEC HMS Model Development and Calibration: Numerical models for the flood simulation and hazard maps generation consisted of developing an upstream hydrologic model, and a two-dimensional (2D) hydraulic model of the main watershed's main tributary and its floodplain. The methodology adopted by the project were previously established during the Phil-LiDAR 1 Project implemented by Caraga State University for the river basins and watersheds in the Caraga Region ((Makinano-Santillan et al., 2015; Amora et al., 2015; Makinano-Santillan et al., 2016a; Santillan et al., 2016). Details about the methodology are briefly discussed here.

A pair of upstream hydrologic model and 2D hydraulic model was prepared for each of the 14 watersheds within the ARB. The purpose of the hydrologic model is to simulate the basic watershed hydrologic processes that consist of runoff generation from rainfall, its transformation and combination with baseflow, including its routing along the channels towards the watershed's outlet (USACE, 2000). The hydrologic models were all based on the Hydrologic Engineering Center Hydrologic Modeling System (HEC HMS) Version 3.5, a system designed to simulate the precipitation-runoff processes of dendritic watershed systems and is also applicable in large river basin water supply, flood hydrology and small urban or natural watershed runoff (USACE, 2016). HEC HMS modelling is reliant on three components namely the basin model, meteorological model and a set of control specification. The basin model or the physical representation of the sub-basins and the river system was prepared in ArcGIS 10.2 using the HEC-GeoHMS extension. It was used to discretize the each watershed into sub-watersheds, and to reproduce topologically-correct stream networks by utilizing the surface topography information from the $10-\mathrm{m}$ DEM as the origin of the boundaries and stream network. This
DEM was generated from RADARSAT-2 data gathered during 2012-2013 (Ramirez, 2014), and provided to the project by the DREAM Program of the University of the Philippines-Diliman. Parameters of the model such Curve Number (for runoff computations) and Manning's roughness were estimated from a 2017 land cover of the ARB (Figure 3). The land cover map was derived through Maximum Likelihood classification of ten (10) Landsat 8 OLI images under path 112 and rows 54 and 55 of the Worldwide Reference System (WRS) where the ARB is entirely contained. Processing such number of images was necessary in to in order to create a complete land cover of ARB (i.e., no missing data due to cloud cover). All images were downloaded as Standard Terrain Correction L1TP products from the United States Geological Survey (USGS) Earth Explorer website (http://earthexplorer.usgs.gov/). The land cover contains 16 classes, and has an overall classification accuracy of $91.5 \%$ based on 1,600 ground truth pixels. The User's and Producer's Accuracies range from $85 \%$ to $99 \%$.

All estimated parameters were integrated to the basin model file and imported to HEC HMS for the final model setup. The meteorological model, rainfall data from the Advance Science and Technology Institute - Department of Science and Technology (ASTI-DOST) stations and control specifications indicating the simulation period were created in HEC HMS. The meteorological model utilizes the rainfall data from rainfall stations within and in the vicinity of the river basin. After completing the set-up, the HEC HMS model of each watershed was calibrated using observed discharge datasets to ensure that the model can calculate discharge hydrographs within acceptable levels of accuracy. For this purpose, the model evaluation guidelines of Moriasi et al (2007) were used. A HEC HMS model shall have at least "Satisfactory" performance in order to be suitable for use in flood modeling. The Nash-Sutcliffe Coefficient of Model Efficiency (NSE), percentage bias 
(PBIAS), and the RMSE-observations Standard Deviation Ratio (RSR) were used to evaluate the performance of model.

\subsubsection{HEC RAS Model Development and} Calibration: The Hydrologic Engineering Center River Analysis System (HEC RAS) was utilized to derive 2-dimensional flood depth and hazard maps. The HEC RAS model was developed by first generating geometric representations of the rivers and floodplains. The 1-meter spatial resolution LiDAR digital terrain model was utilized as the primary source of elevation data for the model simulations. The Manning's surface roughness coefficients of the river and floodplain portions were extracted from land cover maps derived from the analysis of Landsat 8 OLI images. Unsteady 2D flow simulation module of the HEC RAS model was used to estimate flood depth for different rainfall scenarios.

One of the flood prone cities within the ARB is Butuan City. Being located at the downstream-most portion of the ARB just before its outlet, a HEC HMS model of the whole basin was prepared consisting of 538 sub-basins (average area of $22.5 \mathrm{~km} 2$ ). A HEC RAS model was also prepared for the entire city. The same datasets (e.g., 10-m DEM, 1-m LiDAR DTMs, land cover map from Landsat 8 OLI) were also used in preparing the two models.

\subsection{Flood Hazard Maps Generation}

By combining calibrated HEC HMS and HEC RAS models, flood models were generated to simulate hypothetical extreme rainfall events of various rain return periods such as 2-year, 5year, 10-year, 25-year, 50-year and 100-year. The rainfall data in the form of Rainfall Intensity Duration Frequency (RIDF) curves obtained from the Philippine Atmospheric Geophysical and Astronomical Services Administration (PAGASA) was used as an input in calibrated HEC HMS models to generate discharge hydrographs that is, consequently, used as inputs in HEC RAS models. After simulation, maximum depth grids for each scenario were generated which were then categorized based on its corresponding flood hazard level. The categories are low (depth less than $0.50 \mathrm{~m}$ ), medium (depths from $0.50 \mathrm{~m}$ to $1.50 \mathrm{~m}$ ) and high hazard (depths greater than $1.50 \mathrm{~m}$ ).

To determine the reliability and accuracy of the generated flood hazard maps, flood map validations were conducted (Figure 4). Pre-determined random locations within the floodplains of the river basin were visited to verify if they were flooded or not during recent flood events. To validate the results, the actual flooding data from the field were compared to the flooding that was generated by the flood model. The overall accuracy of the flood hazard maps were dependent on the total number of correctly predicted points over the total number of points collected. The Root Mean Square Error (RMSE) of the flood depth maps were also computed thru comparison of the measured and model-simulated flood depth at different locations within the floodplains of the river basin. A measure of fit known as " $F$ Measure" was also utilized to determine if the flooding extent in the map is similar to that on the ground (Breilh, et al., 2013).

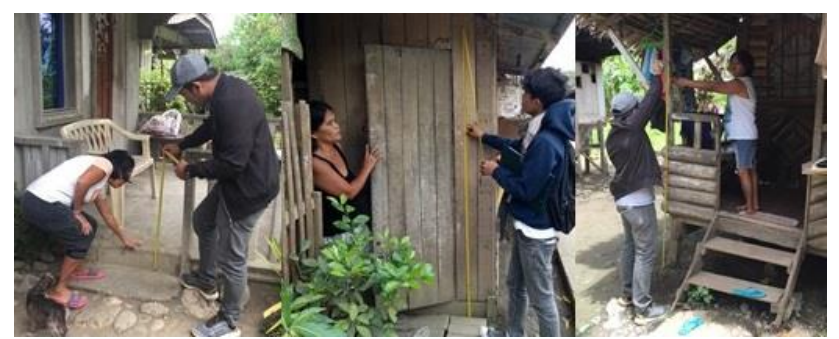

Figure 4. Example photos of flood map validation surveys.

\subsection{Development of Online Rainfall and Water Level Monitoring Systems and Other Web Applications}

In addition to the flood hazard maps produced by the project, online monitoring systems were also developed to monitor the rainfall status within specific municipalities and water level status of its major rivers. The online monitoring system is composed of the rainfall monitoring system and water level monitoring system (Figure 5).

The rainfall monitoring could be accessed at http://monitoring.geosafer-mindanao.org/rainfall/. This system displays the status of the ASTI-DOST Automated Rain Gauges (ARG) for the entire coverage area and was designed to be userfriendly since the target viewers of this system are the general and common public. The current and time-series rainfall 
intensities and the accumulated rainfall for the last 24 hours are displayed for each ARG. Through this monitoring system, rainfall status for a specific municipality/city or province could easily be monitored and understood by the end-users.

The water level monitoring system, on the other hand, was developed to straightforwardly monitor the current water level of a specific major river within the project area. This system also displays the time-series water level data for the last 24-hours and the corresponding spilling levels of the rivers recorded by the Automated Water Level Sensors (AWLS) so that the viewers would determine the spilling status of the rivers monitored. This system could be accessed at http://monitoring.geosafermindanao.org/waterlevel/.

The generated flood hazard maps for all the river basins covered by the project area for each corresponding rain return period were also uploaded in the official website of the project (http://geosafer-mindanao.org/) so that the concerned public including the regional line agencies and other government agencies could directly access and download the maps for their reference (Figure 6).

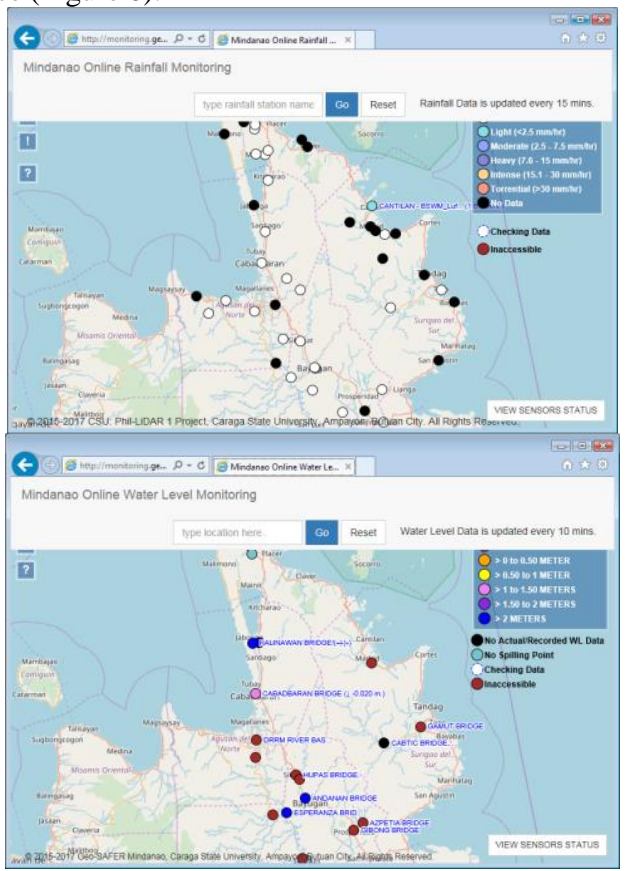

Figure 6. Online rainfall and water level monitoring systems developed to facilitate flood hazard information dissemination.

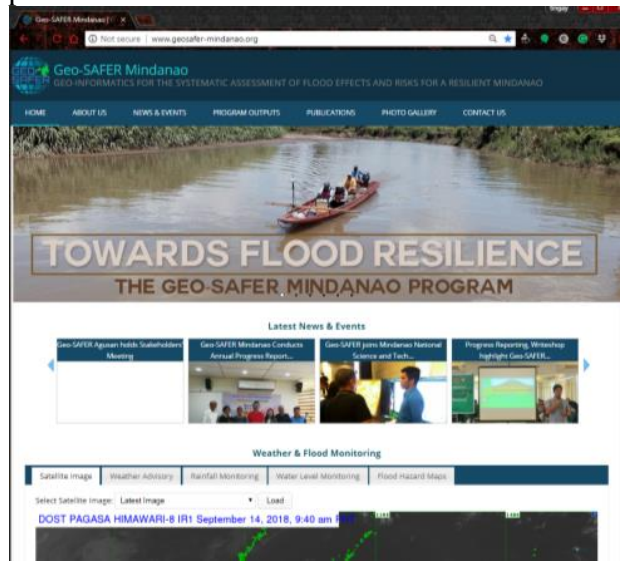

Figure 6. The Geo-SAFER Mindanao project website which can be accessed at http://www.geosafer-mindanao.org/.

\section{RESULTS AND DISCUSSION}

\subsection{Accuracy of the Flood Models and Flood Hazard Maps}

An example result of HEC HMS model calibration is shown in Figure 7. The result is for the calibration of the ARB HEC HMS Model using measured discharge hydrographs at Dankias Station which is located a few kilometrs upstream of the main outlet in Butuan City. Based on the model performance evaluation, the overall performance of the hydrologic model before calibration is "unsatisfactory" (NSE=-4.41, PBIAS=-19.32, and RSR=2.33) which is very noticeable in the comparison between the observed and simulated hydrographs. After the calibration, the statistics improved (NSE $=0.93$, PBIAS $=-2.67$, and $\mathrm{RSR}=0.26$ ), indicating a very good model performance.

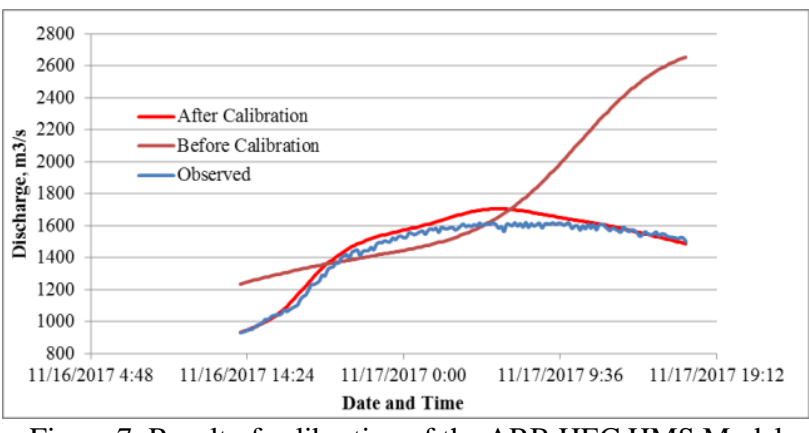

Figure 7. Result of calibration of the ARB HEC HMS Model using measured discharge hydrographs at Dankias Station which is located a few kilometrs upstream of the main outlet in Butuan City.

On the other hand, an example result for validating flood hazard maps generated by the numerical models is shown in Table 1 . The result is for the validation of flood hazard maps generated for Butuan City for the Tropical Storm "Seniang" event which occurred on December 2014. The accuracy of the flood map was $70.59 \%$, with an $\mathrm{F}$ value of 0.5 , indicating intermediate fit.

\begin{tabular}{|l|c|c|c|c|}
\hline & $\begin{array}{c}\text { Actual } \\
\text { Flooded }\end{array}$ & $\begin{array}{c}\text { Actual Not } \\
\text { Flooded }\end{array}$ & Total & $\begin{array}{c}\text { User's Accuracy } \\
(\%)\end{array}$ \\
\hline Model Flooded & 32 & 20 & 52 & 61.54 \\
\hline Model Not Flooded & 10 & 40 & 50 & 80.00 \\
\hline Total & 42 & 60 & 102 & \multirow{2}{|l}{} \\
\cline { 1 - 4 } Producer's Accuracy (\%) & 76.19 & 66.67 & \multicolumn{2}{|l}{} \\
\cline { 1 - 3 } Overall Accuracy (\%): & 70.59 & \multicolumn{2}{|l|}{}
\end{tabular}

Table 1. Example result of flood map validation.

\subsection{Flood Hazard Maps for Various Rainfall Scenarios}

Typical examples of flood hazard maps generated and disseminated by the project are shown in Figure 8. The maps shown were generated for Butuan City.

\subsection{Online Hazard Information Dissemination}

Online means were resorted to promote more awareness to vital information such as flood hazard maps and monitoring systems that could be utilized as a tool for preparation and mitigation of hazards brought by floods to our community. However, though internet and accessing of different websites were pervasive in this era, public awareness for digital flood hazard maps and online rainfall and water level monitoring web applications were low compared to the targeted supposed-to-be end-users. Internet citizens or 'netizens' today are more engaged on social media platforms for networking, communication, posting entries, marketing, publishing, soliciting services and many more. 


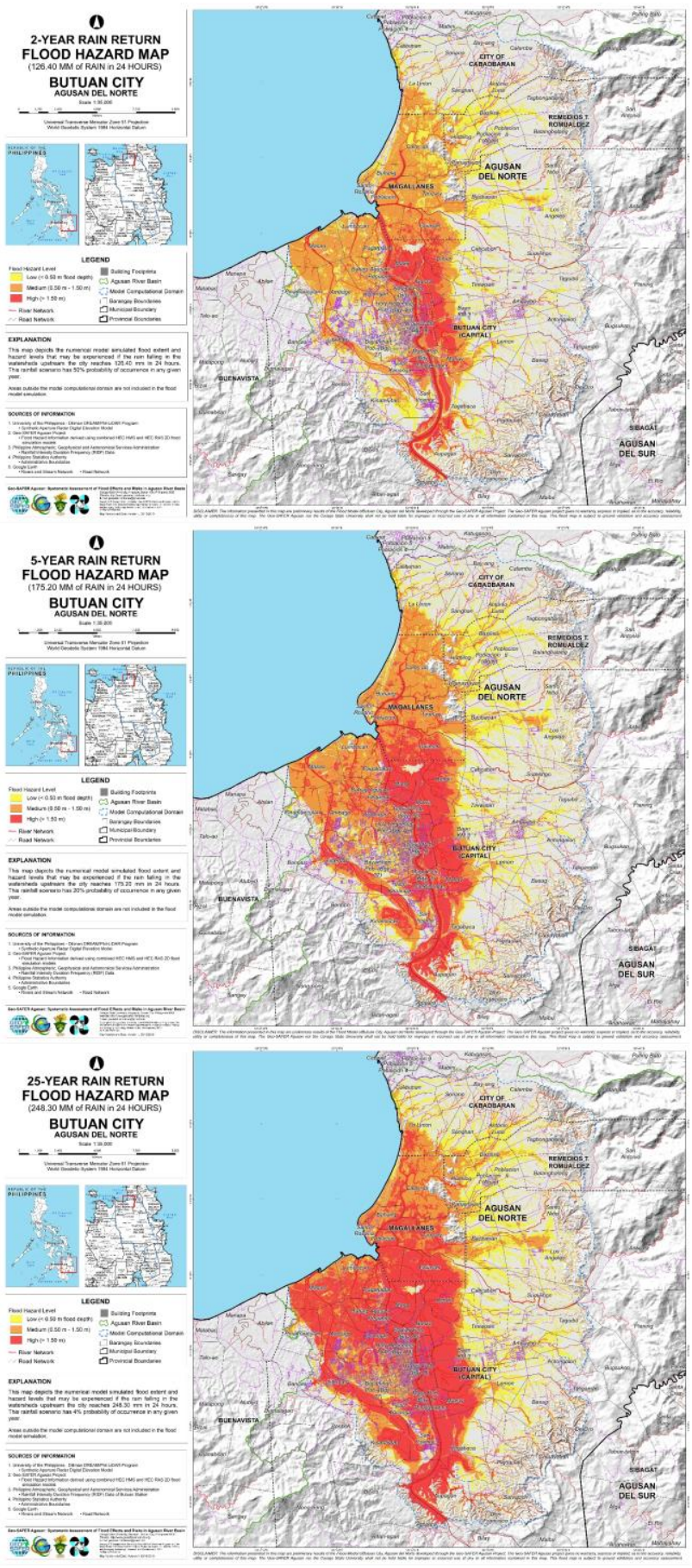

Figure 8. Examples of flood hazard maps generated for Butuan City for different extreme rainfall scenarios.

Given the said fact, the project viewed this situation as an opportunity to promote extensive awareness and to stimulate netizens to engage more in disaster readiness and in mitigating the risk of flood disasters. Thus, the project initiated another means of promoting the flood hazard maps and monitoring systems to the concerned public. Since Facebook is one of the most popular free social networking website in the Philippines with 67 million total number of monthly active Facebook users (We Are Social, 2018; Hootsuite, 2018), the project established a Facebook page (https://www.facebook.com/geosafercaraga/) where the flood hazard maps, online monitoring systems and other information generated by the project are persistently disseminated and promoted, especially during extreme rainfall events.

The project initiated flood hazard information dissemination procedures to monitor the weather, rainfall and water level status of the project areas when an extreme rainfall event threats to hit the concerned areas. The flood hazard monitoring and information dissemination is implemented to broadcast updated information from PAGASA, an attached agency of the DOST mandated to protect lives and properties through timely, accurate and reliable weather-related information and services such as rainfall advisories, weather bulletins, weather outlooks, weather forecasts and other relevant information; and to disseminate rainfall and water level status from the online monitoring systems, including the flood hazard maps that could be used as reference for decision making and spreading flood hazard information, through the Geo-SAFER Facebook page (https://www.facebook.com/geosafercaraga/) where various concerned local government units (LGUs), local disaster risk reduction and management offices (LDRRMOs) and local response teams are tagged and mentioned in every post to keep them informed with up-to-date relevant information (Figure 9).

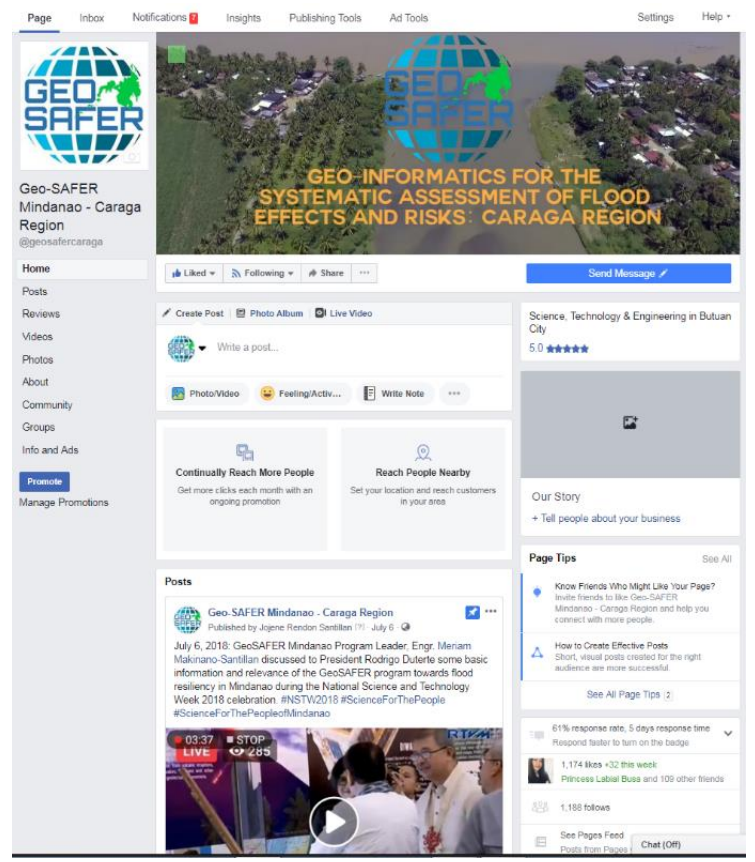

Figure 9. Facebook page of the Geo-SAFER Agusan project which facilitated near-real time flood hazard information dissemination.

In addition to the utilization of Facebook, the monitoring team also established a direct and active communication with the local disaster risk reduction and management offices (DRRMOs) of each city/municipality covered by the project. Conversely, prior to the direct communication between the project and the local authorities, the project conducted various courtesy meetings to the Regional Disaster Preparedness Committee, Regional Disaster Risk Reduction and Management Council and Provincial Disaster Prevention and Mitigation Committee to formally present the project, its objectives and outputs and how all entities including the general public could benefit from this project. Henceforth, the project gained the support of the committees in achieving its goals of providing accurate flood hazard maps and other outputs to the community and 
secondarily, the project also helped the committees in the dissemination of relevant flood hazard related information to the public. Consequently, during heavy rainfall events, the monitoring team of the project is dynamically communicating respective DRRMOs to provide relevant information that could aid them in saving the lives of their people. Shown in Figures 7 and 8 are actual photos of the Geo-SAFER team while monitoring tropical cyclones that hit and threatened the safety and well-being of the people in the region while disseminating relevant information through the project website and social media platforms.

\subsection{Recent Experiences in Hazard Information Dissemination}

As of October 2018, four tropical cyclones were able to affect the areas covered by the Geo-SAFER Agusan project namely Tropical storm Kai-tak (local name "Urduja") and Typhoon Tembin (local name "Vinta") both on December 2017, Tropical Depression "Agaton" on January 2018 and Tropical Storm Sanba (local name "Basyang") on February 2018. All of these events were closely monitored by the project team (Figure 10). During such events, the Geo-SAFER Agusan team made use of the developed online monitoring systems. The Maximum Rainfall Intensities and Total Accumulated Rainfall over the last 24 hours of specific areas were observed in the rainfall monitoring; while Actual/Recorded Water Level and Remaining Height to Spill in both Left and Right Banks of identified rivers were tracked for the water level monitoring.

The systems also made use of the table of Extreme Values (in $\mathrm{mm}$ ) of Precipitation for the last 24 hours (see Table 1) on Agusan river basin provided by the DOST-PAGASA. The system gives notifications via the email addresses of the GeoSAFER Agusan monitoring team once the accumulated rainfall of a certain area reached half of any of the values which corresponds to a specific rain return period (in years) of the river basin to where it belongs. The said data served as the team's guide on what specific flood hazard map should be used by the concerned LGUs from time to time. The team regularly disseminated information to the concerned LGUs via text/call and social media accounts which is also accessible to the public. Local DRRMOs of concerned areas provided responses/confirmations from the information disseminated by the tem also via text/call and/or sharing the project's Facebook posts on their agency's official accounts. The monitoring team has also regularly shared weather updates, advisories, forecasts, and actual posts from citizens and LGUs of affected areas on its Facebook page before, during and after weather disturbances. In addition, the project's Facebook page played a big role in the wide scope of disseminating flood hazard-related information given the increased amount of the page's likes and engagements with its viewers and followers over the last few months upon its creation. As of January 10, 2019, the Facebook page has 1,331 likes and 1,346 followers.

\section{CONCLUDING REMARKS}

In developing a method for disseminating flood hazard and any related information, the flood hazard maps generated by the project were made more accessible to the LGUs and the public through the web and social media. In addition, interpretation and utilization of these maps were made easier for the end-users by utilizing the online web applications developed by the project such as the rainfall monitoring and water level monitoring systems which display timely information that is significant in monitoring procedures during heavy rainfall events that can cause flooding.

Through this method of disseminating relevant flood information to the LGUs and the general public, the local government DRRMs became more guided on their flood disaster preparations, local monitoring and decision making, in fact, the effectiveness and significance of the project's outputs and its systems were acknowledged and confirmed by the LGUs and the general public.

On the other hand, maximum effort has been exerted over the years by the mandated authorities such as the DOST, other assisting agencies and government-funded projects, such as the Geo-SAFER Agusan, to capacitate the people and communities and help them to prepare for an impending flood hazard and prevent or mitigate casualties and damages, however, disaster risk reduction and mitigation is complex and does not work without the full support and cooperation of the stakeholders. While it is the government's responsibility to protect and guide its people through its DRRM programs, the community has also a vital role to carry out. The people must also cooperate, adapt and be open to the initiatives of the government, for in the end, it is the people who will greatly benefit from these projects.

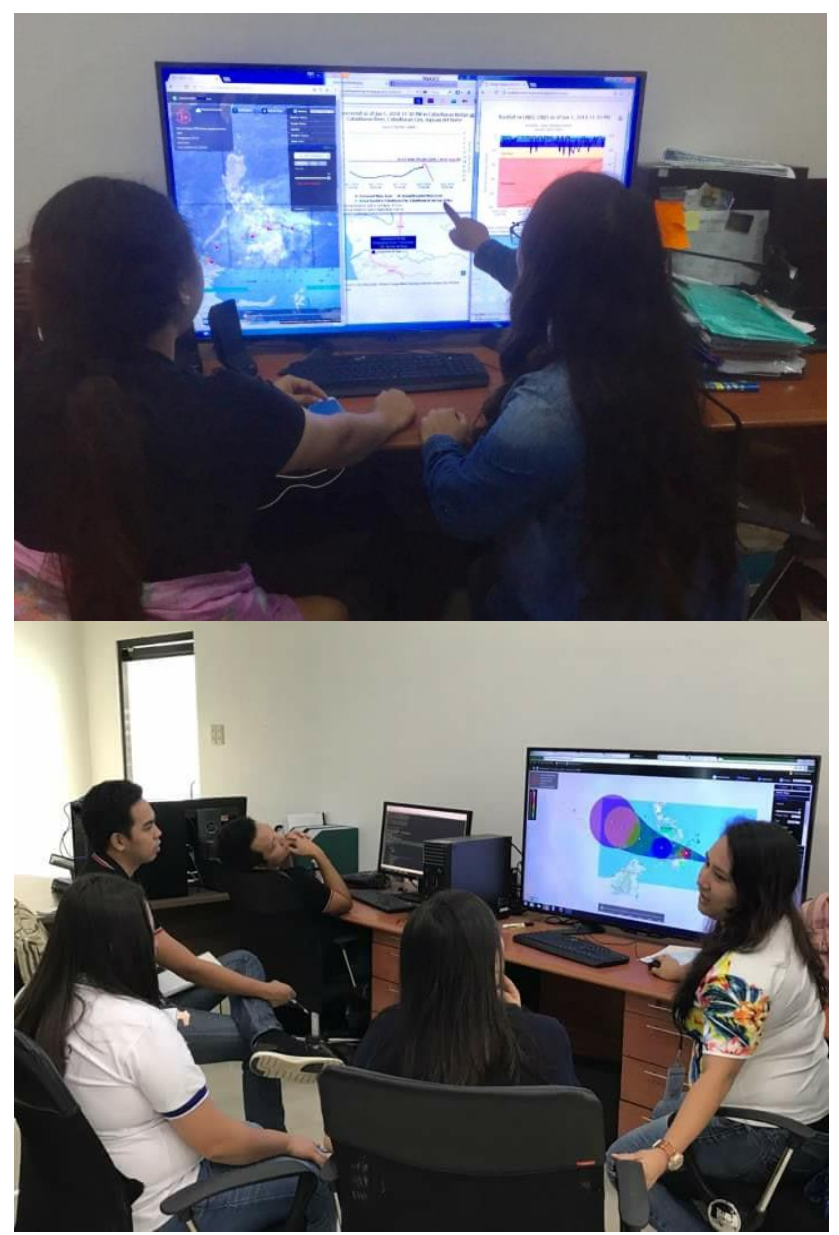

Figure 8. Photos of the team while monitoring Tropical Depression "Agaton" on January 2, 2018 (above) and Tropical Storm Sanba (local name "Basyang") before it hit the region on February 11-15, 2018. 


\section{ACKNOWLEDGEMENTS}

The works presented in this paper are outputs of the Geo-SAFER Agusan, one of the component projects of Geo-SAFER Mindanao ("Geo-informatics for the Systematic Assessment of Flood Effects and Risks for a Resilient Mindanao"), a research program funded by the Philippine Council for Industry, Energy and Emerging Technology Research and Development of the Department of Science and Technology (PCIEERD DOST). We gratefully acknowledge PCIEERD DOST for the financial support.

\section{REFERENCES}

Amora, A.M., Santillan, J.R., Makinano-Santillan, M., Marqueso, J.T., 2015. Flood hazard mapping of Mainit-Tubay River Basin, Mindanao, Philippines using LID AR and Numerical models. Proceedings of the 36th Asian Conference on Remote Sensing 2015 (ACRS 2015) - Fostering Resilient Growth in Asia, Quezon City, Metro Manila, Philippines.

Asian Development Bank, 2004. Technical Assistance to the Republic of the Philippines for a Master Plan for the Agusan River Basin. Retrieved March 18, 2018, from https://www.adb.org/sites/default/files/projectdocument/69512/tar-phi-36540.pdf.

ABS-CBN News, 2018. Philippines is world's top social media user: study. Retrieved March 19, 2018, from http://news.abscbn.com/focus/02/01/18/philippines-is-worlds-top-social-mediauser-study.

Breilh, J., Chaumillon, E., Bertin, X., Gravelle, M., 2013. Assessment of Static Flood Modeling Techniques: Application to Contrasting Marshes Flooded During Xynthia (Western France). Natural Hazards and Earth System Science, 13(6), 1595-1612.

Hewitt, K., 1997 Regions of risk: a geographical introduction to disasters. Harlow, UK: Addison Wesley Longman.

Lagmay, A.M.F.A., Racoma, B.A., Aracan, K.A., Alconis-Ayco, J. and Saddi, I.L., 2017. Disseminating near-real-time hazards information and flood maps in the Philippines through Web-GIS. Journal of Environmental Sciences, 59, pp.1-14.

Laituri, M. and Kodrich, K., 2008. On line disaster response community: People as sensors of high magnitude disasters using internet GIS. Sensors, 8(5), 3037-3055.

Makinano-Santillan, M.,Santillan, J.R., 2015. Flood hazard mapping of river basins in Caraga Region, Mindanao, Philippines through the CSU Phil-LiDAR 1 Project. Proceedings of the 36th Asian Conference on Remote Sensing 2015 (ACRS 2015) - Fostering Resilient Growth in Asia, Quezon City, Metro Manila, Philippines.

Makinano-Santillan, M., Santillan, J.R., Amora, A.M., Marqueso, J.T., Cutamora, L.C., Serviano, J.L., Makinano, R.M., Asube, L.C.A., 2015. Assessing the impacts of flooding in Tago River Basin, Mindanao, Philippines through integration of high resolution elevation datasets, landsat image analysis, and numerical modelling. Proceedings of the 36th Asian Conference on Remote Sensing 2015 (ACRS 2015) - Fostering Resilient Growth in Asia, Quezon City, Metro Manila, Philippines.
Moriasi, D. N., Arnold, J. G., Van Liew, M. W., Bingner, R. L., Harmel, R. D. and Veith, T. L., 2007. Model evaluation guidelines for systematic quantification of accuracy in watershed simulations. Transactions of the ASABE, 50, 885-900.

Perry, R.W. and Nelson, L., 1991. Ethnicity and hazard information dissemination. Environmental Management, 15(4).

Santillan, J. R., Amora, A. M., Makinano-Santillan, M., Marqueso, J. T., Cutamora, L. C., Serviano, J. L., and Makinano, R. M, 2016a. Assessing the impacts of flooding caused by extreme rainfall events through a combined geospatial and numerical modeling approach. International Archives of the Photogrammetry, Remote Sensing and Spatial Information Sciences, XLI-B8, 1271-1278.

Santillan, J.R., Marqueso, J.T., Makinano-Santillan, M. and Serviano, J.L., 2016b. Beyond flood hazard maps: detailed flood characterization with Remote Sensing, GIS and 2D modelling. International Archives of Photogrammetry, Remote Sensing and Spatial Information Sciences, 42(4W1), 315-323.

Shklovski, I., Palen, L. and Sutton, J., 2008, November. Finding community through information and communication technology in disaster response. Proceedings of the 2008 ACM conference on Computer supported cooperative work. ACM.

USACE, 2000. Hydrologic Modeling System HEC-HMS Technical Reference Manual, United States Army Corps of Engineers, Hydrologic Engineering Center, Davis, California.

USACE, 2016. HEC-RAS River Analysis System Hydraulic Reference Manual, Institute for Water Resources, Hydrologic Engineering Center, Davis, CA.

We Are Social, 2018. Digital in 2018 in Southeast Asia Part 2 South-East. Retrieved March 19, 2018, from https://www.slideshare.net/wearesocial/digital-in-2018-insoutheast-asia-part-2-southeast-86866464. 